\title{
Corpo, cultura e Paulo Freire: a capoeira COMO POSSIBILIDADE DE UMA EDUCAÇÃO NA PERSPECTIVA DA EMANCIPAÇÃO HUMANA
}

\author{
ANASTÁCIA SCHROEDER \\ JOANA RITA LOPES VIERA \\ Maria Cecília de Paula Silva \\ Universidade Federal da Bahia (UFBA), Salvador, Bahia, Brasil
}

Resumo: O presente artigo, de base teórica, objetiva relacionar conceitos freirianos de ser mais, conscientização, liberdade, ler o mundo, situações limite, oprimido opressor, com os fundamentos e o universo simbólico da Capoeira, manifestação cultural afro-brasileira de luta e resistência de povos historicamente marginalizados, a fim de possibilitar uma educação libertária com base na Cultura. Por apresentar fundamentos configurados na corporeidade e em simbologias, como as cantigas, que conferem pertencimento social e histórico, além da valorização positiva de identidades historicamente silenciadas, a prática da capoeira configura-se como potencial manifestação cultural em direção ao SerMais, levando a inserção crítica de oprimidos na realidade, para que nela atuem voltados a emancipação humana.

Palavras-chave: Capoeira. Corpo. Paulo Freire. Educação libertadora.

INTRODUÇÃO

A experiência cotidiana de viver e estar sendo em sociedade permite a observação ainda atual da dicotomia oprimidos e opressores desde o andar nas ruas, nas relações em instituições de trabalho e ensino e nas relações 
interpessoais decorrentes de processos culturais. Pessoas vivem e convivem em um sistema que as lê e classifica conforme suas possibilidades de atender as demandas do capital, às suas características étnicas e cor de pele, ao seu gênero, enfim, as suas condições corporais, culturais e sociais.

Somos estruturalmente segregados e coletivamente seduzidos a atender padrões para nos sentirmos, desesperadamente, incluídos. Mas incluídos para as óticas da dominação, que torna as pessoas marginalizadas pelo sistema dominante e desprovidas de humanidade. Torna-se necessário assim a libertação da alienante acomodação às opressões diárias, indignandonos com as situações recorrentes nos ambientes que convivemos para atuar conscientemente neles: um processo que requer a humanização na direção de sermos mais, nossa vocação humana e histórica (FREIRE, 1987).

Nesta disputa diária de corpos exauridos pelos excessos do trabalho, pelas opressões de gênero, raça e classe social, onde o cuidado interpessoal é ofuscado pela dialética de uma sociedade doentia, se torna imprescindível pensar em uma educação voltada ao Ser Mais (FREIRE, 1987).

Educação aqui considerada como ação política que atua no sentido libertador considerando "o papel das emoções, dos sentimentos, dos desejos, dos limites; a importância da consciência na história, o sentido ético da presença humana no mundo, a compreensão da história como uma possibilidade jamais como uma determinação" (FREIRE, 2015, p. 23). Processo educativo que envolve mulheres, homens, crianças e seus instrumentos sutis de sentir/ler/viver seus mundos; pela cosmovisão e percepção de seus corpos e emoções, suas culturas, suas histórias. Uma educação que supere a dicotomia seres-humanos/mundo, enfatizando seu estar sendo nele, com ele e com as/os outros que também o habitam, de maneira permanente e irrecusável (FREIRE, 1987). É necessário, em decorrência, atendermos às propostas freirianas de uma educação que forme pessoas conscientes de sua presença no mundo (FREIRE, 2015), atuem sobre suas realidades a fim de realizar as transformações necessárias de suas condições.

De acordo com as ideias de Paulo Freire, a conscientização do mundo torna viável a consciência de si, o que inviabiliza a imutabilidade do mundo e suas realidades, nos fazendo não apenas seres que estão no mundo, mas com o mundo e com os outros. Temos a possibilidade de intervir neste mundo, o que nos confere historicidade e a capacidade de fazer história (FREIRE, 2015).

As inúmeras manifestações culturais como a Capoeira, o Sambade-roda, Jongo, Maracatu, Congadas etc., possuem lógicas diferenciadas de aprendizado e transmissão do conhecimento. Estabelecem fortes conexões com a corporeidade e oralidade, explorando rituais que transbordam 
valores humanos e históricos de populações historicamente e socialmente marginalizadas. Possuem características específicas de resistência, afirmação de identidade e luta das classes populares (FALCÃO, 1991). Com base nas indignações de Freire, as resistências culturais são manhas necessárias à sobrevivência física e cultural destes e destas que ainda são oprimidos pelo sistema de dominação (FREIRE, 2015, p. 91). Essa resistência, por sua vez, passa a conferir a visão crítica perante seu ser/estar no mundo, condizente com a visão libertária e emancipatória de educação que defenderemos neste artigo.

O corpo humano é aqui considerado como "um meio de produção da consciência real, porém, não se reduz a essa consciência, e nem esta se reduz ao corpo. O corpo é uma realidade imediata: a da ação de transformar/ apreender o real. Isto é, o corpo humano é a realidade imediata da consciência" (SILVA, 2009, p. 68). Ao tratar desse tema, Antonacci (2014, p. 125) define corpos africanos que, entendidos como elementos da natureza, assumem a representação de expressão cultural vivenciada, "cosmovisões e formas de inserção no mundo. Mas percepções externas a corpos sem fronteiras vêm seus costumes e tradições carregados de preconceitos e divergências, em termos de formas de ler povos e culturas estranhas ao mundo europeu". Ao se falar do universo afro-brasileiro, o foco do corpo como expressão da simbiose natureza e cultura recai "na perspectiva que herdeiros de matrizes africanas vivem intercâmbios cósmicos [...], sendo seus corpos como 'arquivos vivos' de memórias sem fronteiras" (ANTONACCl, 2014, p. 155).

A capoeira, uma das mais significativas manifestações da cultura corporal afro-brasileira, se apresenta então como uma possibilidade geradora de compreensões de interseções entre aspectos ambientais, culturais, sociais e educativos tecidos pela corporeidade e por seu vasto universo simbólico, apresentados na roda de capoeira'. A controvérsia de sua origem se baseia na argumentação apresentada por alguns autores dela estar relacionada às danças rituais do sudoeste da África Bantu, como o N'golo ou dança da Zebra, enquanto outros argumentam que sua origem é afro-brasileira, criada a partir da necessidade de libertação da opressão do regime de escravidão. Ao longo de sua história ganha variadas denominações que até hoje geram embates e conflitos, como dança, jogo, luta, arte, esporte nacional e atividade esportiva.

Esse universo abriga saberes orais e rituais significativos que remetem a uma ancestralidade com aspectos referentes ao processo histórico e identitário de resistência das camadas subalternas (ABIB, 2005). Como exemplo, as cantigas de capoeira possuem conotações referentes ao processo de escravização e resistência dos afro-brasileiros no Brasil, marca expressiva desse universo de simbologias. 
A capoeira pode ser tratada como importante elemento cultural e educacional por envolver a perspectiva de compreensão integral do corpo, considerando aspectos da expressão corporal, musical, social, ritualístico e filosófico, com possibilidade de se discutir valores como solidariedade, coletividade, cooperação, companheirismo e autonomia, perspectivando tornar-se sujeito de sua história.

Esta prática cultural pode então ser de suma importância para a práxis de uma educação para a emancipação humana, considerando a conjuntura política brasileira e os atuais desmontes da educação. Além disso, a questão do pensar a Educação e suas relações com o corpo e a cultura ainda são pouco exploradas em trabalhos acadêmicos, ressaltando a emergência de estudos que focalizem tais categorias.

Portanto, objetivamos, neste artigo, apresentar as relações possíveis entre Corpo, Cultura (aqui representada pela Capoeira) e Educação através de alguns conceitos explicitados por Freire: ser mais, conscientização liberdade, ler o mundo, situações limite, oprimido opressor. Primeiramente iremos expor as conceituações freirianas que serão aqui consideradas, seguidas de um breve histórico da Capoeira e suas vertentes, para, então, estabelecer conexões entre a prática cultural e os princípios emancipatórios freirianos, na busca por uma educação libertadora através da Cultura.

\section{Contribuições de Paulo Freire Para uma educação para a emancipação HUMANA}

No tempo presente, descortina-se uma realidade político-social repleta de problemáticas relativas à educação. De fato, a educação atual está edificada no valor do ter e não no valor do ser, na qual a grande massa da humanidade está subjugada a um sistema tecnológico e comercial, com objetivo de gerar ondas de consumidores descartáveis e compulsivos que enriquecem corporações cada vez menos numerosas e mais poderosas. Nesse cenário encontra-se uma educação que, vinculada a todo esse processo de massificação está ao serviço da reprodução do sistema, pois é moldada por uma socialização passiva e competitiva, produzindo mentes acríticas e corpos obedientes.

Perante essas problemáticas, a leitura e conhecimento das obras de Paulo Freire traduzem-se em palavras de natureza profundamente filosófica e conceitual, contextualizadas em, ser mais, conscientização, liberdade, ler o mundo, situações limite, oprimido opressor, as quais inquietam e ampliam o estudo entre Corpo, Cultura e Educação. 
Nesse sentido, Paulo Freire defende que a educação é o meio privilegiado para fomentar uma tomada de consciência que faz submergir na mulher e no homem uma atitude crítica, com a qual se aprende a decidir e a escolher, libertando-os das correntes da submissão e da massificação.

Ainda presos aos liames da massificação, assiste-se a uma práxis pedagógica assente numa educação bancária, a qual inclui como necessidades básicas de aprendizagem conteúdos inertes que negam a problematização, o diálogo e a participação. Em teoria, reduz-se a palavra a um verbalismo que prima pela memorização mecânica e não instiga os homens e as mulheres a superarem posições ingênuas face ao mundo que os rodeia. É nessa forma de ser e de estar que reside o medo da própria liberdade, o medo de eliminar a consciência hospedeira, na qual o homem, impossibilitado de superar a massificação, continua numa situação de heteronomia (FREIRE, 1987).

Pelo que se entende ser necessário compreender que a práxis humana nasce da dialética entre a ação e a reflexão sobre o mundo e que a sua visão espontânea e ingênua não passa duma aproximação à realidade, é apenas a experiência da realidade que se procura. Não podemos considerar que esta simples aproximação à realidade seja vista como conscientização, já que esta consiste num todo mais alargado - a "elevação do pensamento" tido como um movimento que ultrapassa a extensão da realidade espontânea e impulsiona para a extensão crítica da realidade, posicionando o homem como objeto cognoscível e dentro dessa realidade, ele adquire uma posição epistemológica (FREIRE, 1987).

Deste modo, conscientização significa um compromisso histórico, que inclui mulheres e homens numa ação crítica perante a história, assumindo o papel de sujeito que cria e recria o mundo. No entanto, a conscientização não está somente fundamentada, por um lado, na consciência e por outro no mundo, mas antes na estreita ligação consciência-mundo, e neste contexto pode-se referir que todo o processo de conscientização revela uma realidade transformada que deve ser objeto de reflexão crítica continuada, pois o contrário representa uma posição ingênua, submersa em dimensões opressivas.

Freire (1987) considera que a prescrição é a imposição de escolher entre uma consciência ou outra. Isso demonstra que toda a opressão é uma realidade desumanizante "que atinge aos que oprimem e aos oprimidos" (FREIRE, 1987, p. 34-45). O maior entrave à libertação dos oprimidos é o medo da liberdade que emerge da prescrição, e os impede de alcançar a autonomia. Esta forma de pensamento faz concluir que, no intuito de criar uma consciência ao oprimido da sua não liberdade, é necessário que o mesmo 
se torne consciente, lutando internamente para ser autêntico ao libertar-se da alienação, das amarras do opressor, de tornar-se autônomo e criador da sua própria vida.

A prescrição é alienante, pois a consciência "hospedeira" do oprimido rege-se pela consciência do outro - o opressor. A massificação introduzida nas sociedades modernas pode entender-se como opressora, dado converter homens e mulheres em seres passivos, acomodados a uma realidade castradora, dificultando a integração destes no e com o mundo. "A integração resulta da capacidade de ajustar-se à realidade, acrescida da vontade de transformá-la a que se junta a de optar, cuja nota fundamental é a criticidade" (FREIRE, 1996, p. 42).

Essa integração dá-se por um movimento dinâmico que se desdobra em opção e ação transformadora de um sujeito comprometido com o mundo, concretizando a autonomia. Perentoriamente, "denuncia que as tarefas do homem moderno em vez de serem fruto de decisão consciente a partir da realidade, são decisões de uma elite que por meio da prescrição, massifica, acomoda, rebaixando o homem à condição de objeto, fazendo-o heterônomo" (FREIRE, 1996, p. 43).

No enquadramento destas ideias, o pensamento filosófico freiriano remete-se para a vocação ontológica do ser mais, ou seja, mulheres e homens são vistos como seres integrais, que se (re)constroem ao longo da história, (re) criando a sua existência ao longo da vida, através do trabalho, dos conflitos, do amor, na convivência com o outro, na arte. É nesse movimento, nessa busca que homens e mulheres se lançam na aventura de se conhecer e de ser mais (FREIRE, 1987).

A vocação ontológica do ser mais convida o ser humano a mergulhar no conhecimento de si mesmo e do mundo, bem como no lutar pela afirmação da sua liberdade. A busca de ser mais traduz-se na e pela humanização do mundo, instiga o ser humano à problematização das relações que estabelece com o seu contexto social e cultural e, consequentemente, o desafia a refletir sobre a questão da sua responsabilidade na história. Revela que apesar de estar sujeito a uma programação preestabelecida, o ser humano não é irremediavelmente determinado e condicionado. Pelo contrário, existem inúmeras possibilidades, ao adquirir consciência dos seus condicionamentos, pode intervir com mais autonomia e com mais poder de decisão, ampliar as suas opções, agir com ética e fomentar a estética, não ser apenas objeto, antes sujeito da história (FREIRE, 1994).

Essa busca emancipadora funda-se na profunda convicção dos potenciais humanos que muitas vezes são mutilados pelas realidades 
opressoras. Deste modo, homens e mulheres em partilha desvelam e superam essas realidades de opressão que se manifestam numa busca permanente de ser mais, de humanização.

Ao reconhecerem, homem e mulher, que a sua humanidade é condicionada e negada, torna-se necessária uma luta permanente pela sua humanização e desse ponto nasce a possibilidade de ser mais. Essa luta só tem sentido se for partilhada no diálogo com o outro: "Se o diálogo é o encontro dos homens para ser mais, não pode fazer-se na desesperança. Se os sujeitos do diálogo nada esperam do seu que fazer, não pode haver diálogo. O seu encontro é vazio e estéril. É burocrático e fastidioso" (FREIRE, 1987, p. 47). Assim, propõe-se uma práxis pedagógica que se firma no diálogo e na autonomia, não pactua com a "cultura do silêncio" ou com qualquer "sloganização ideológica" que desvirtuam a relação entre o sujeito e a realidade objetiva.

Nesta linha de argumentação, Freire afirma que a condição existencial (o existir) do homem e da mulher não pode ser "muda" ou "silenciosa", nem alimentar-se de palavras falsas, mas de palavras que têm uma realização transformadora, como espelhado nesta citação "Existir humanamente é pronunciar o mundo, é modificá-lo. O mundo pronunciado por sua vez, se volta problematizado aos sujeitos pronunciantes, a exigir deles um novo pronunciar" (FREIRE, 1987, p. 44).

Na sequência desse processo, em que o diálogo se mostra como o encontro entre os seres humanos, o pronunciar do mundo não termina na relação eu-tu. Na medida em que o homem "pronuncia" o mundo, a sua ação e reflexão gera transformação e, por isso, o diálogo abre um caminho para a conscientização.

A CAPOEIRA COMO EXPRESSÃO CORPORAL: CULTURA DE RESISTÊNCIA E LIBERDADE, DOS QUILOMBOS ÀS CIDADES CONTEMPORÂNEAS

A Capoeira, desde os quilombos à vadiação de rua e até suas diferenciações nas vertentes mais amplamente conhecidas como Angola, Regional e Contemporânea, foi construindo-se e sofrendo influências/ transformações conforme os meios culturais em que se formava e os contextos histórico-político no Brasil. Para Antoniacci (2014, p. 301) "cada cultura forja seu corpo, esculpe e materializa em seus corpos sentidos, espiritualidade, filosofia de vida desde sua lógica e concepção de mundo".

As discussões e controvérsias perante sua conformação se prolongam inclusive no surgimento do termo Capoeira. Waldeloir Rego (2015) nos 
apresenta uma relação semântica de significações do termo, sendo as mais discutidas a derivação do tupi kô-puera (roça abandonada da qual o mato tomou conta), da brava ave denominada capoeira (Odontophorus capueira, Spix), encontrada do Nordeste ao Sul do país, como também aos balaios de transportar galinhas, utilizados por africanos escravizados nas ruas do Rio de Janeiro. Registros artísticos como a aquarela do artista Rugendas, que retratou o encontro de negros de diferentes etnias dançando, sem acompanhamento de instrumentos musicais em encontros escondidos em uma localidade baiana retrata evidências da Capoeira em localidades baianas (ABREU, 2005 apud SCALDAFERRI, 2015). O mesmo autor cita que o local destaca a presença de matas urbanas, virgens ou capoeiras onde se encontravam sítios e quilombos, denotando as relações sociais da capoeira que ocorreram nos centros urbanos, principalmente em cidades portuárias como Salvador, Recôncavo, Rio de Janeiro e Recife.

Oliveira e Leal (2009) argumentam que os primeiros registros historiográficos se concentraram na Capoeira Carioca do século XIX, organizada em Maltas que reunia escravizados cativos com populações marginalizadas urbanas, altamente repreendidas. Os registros datados da época da corte imperial correspondem ao Códice 403, livro de registros de prisões diárias, no qual as ocorrências estavam relacionadas à prática de desordem pública tendo capoeiristas como seus principais praticantes. E na Bahia, as primeiras referências diretas à Capoeira, remetem ao final do século XIX e início do século $X X$, em referência às pesquisas que reconstituíam o cotidiano de "populares" nas ruas de Salvador em decorrência das brigas de "desordeiros e valentões".

No entanto, encontramos no depoimento de Mestre Pastinha, Mestre Noronha e Mestre Bimba, ícones históricos da Capoeira Angola e Regional, respectivamente, referências ao aprendizado de Capoeira com africanos que, quando os introduziram nessa "Arte de Mais Valia" (como disse o africano Benedito à Pastinha) nas duas primeiras décadas do século $X X$, já possuíam idade avançada, sugerindo a presença da Capoeira Angola já no século XIX (SCALDAFERRI, 2015).

Inicialmente o aprendizado da Capoeira se dava nas rodas de rua, em festas de largo populares. A Capoeira foi adentrar os espaços fechados das academias primeiramente na década de 30, com Manoel dos Reis Machado, o Mestre Bimba, criador e difusor da Capoeira Regional. Com os argumentos que a Capoeira Angola já não satisfazia as condições de resposta de uma luta de defesa contra a opressão dos fortes perante os fracos, adicionou assim 
movimentos de artes marciais a então Capoeira Angola, que já possuía como um de seus maiores difusores Vicente Ferreira de Pastinha, o Mestre Pastinha.

Essa fragmentação das artes, sofrendo transformações que marcaram profundamente o histórico da Capoeiragem, ocorreu em consonância e sob influência do período político no qual se encontrava. A Capoeira, criminalizada pelo código penal de 1890, foi perseguida durante toda a república velha, saindo da ilegalidade apenas no governo de Getúlio Vargas, quando Mestre Bimba apresenta sua arte para o atual presidente. A Capoeira, identificada por Mestre Bimba como "Luta Regional baiana", ganha a conotação de "Gymastica Nacional”, ou, como diria Getúlio Vargas, "Esporte genuinamente brasileiro". Esses termos refletem as tendências de nacionalização e esportivização da mesma, fruto do projeto político-ideológico do Estado Novo de modernização da sociedade brasileira e "higienização" das manifestações populares.

Neste momento, demonstrava a busca da legitimação e aceitação social, que indicavam os valores da mestiçagem e da identidade nacional, propostos pela ideologia nacionalista vigente (MAGALHÃES, 2015), também decorrente dos projetos racialistas e racistas das políticas de embranquecimento ocorridas desde a metade do século XIX (OLIVEIRA; $L E A L, 2009)$. Nesses ocorreram repressões às culturas de matriz africana como a proibição da prática da capoeiragem. A diferenciação da capoeira em vertentes distintas levou a tensões, como os defensores da Capoeira Angola, que a caracterizam como a capoeira pura, legítima e autêntica, representante de uma verdadeira tradição negra (MAGALHÃES, 2011).

\section{Corpo, capoeira e Paulo Freire: Possibilidades de uma educação para A EMANCIPAÇÃO PELA CULTURA}

Quando numa roda de capoeira angola, os jogadores, antes do jogo, agacham-se em reverência, e no cantar de uma ladainha, invocam todo um passado de luta e sofrimento; quando se busca nesse momento de celebração, toda a memória e a tradição espiritual de um povo que segue resistindo há séculos de dominação; quando esse diálogo corporal se inicia expressando uma estética que remete a toda uma ancestralidade que incorpora referências rituais de um passado que continua vivo, tatuado no corpo de cada capoeira, talvez possamos compreender um pouco melhor a noção de circularidade do tempo; talvez possamos sentir essa força instauradora de um passado que vigora a cada vez que os acordes de um berimbau ecoam como navalha cortando o ar (ABIB, 2005, p. 109). 
Este autor, ao descrever o início de uma tradicional roda de Capoeira Angola, percorre a lógica diferenciada das manifestações culturais não hegemônicas, como a Capoeira Angola, que tem em sua base de sustentação a oralidade, a memória e ritualidade. Nessas, podemos encontrar fundamentose ensinamentos condizentes com os pressupostos freirianos que consideramos neste artigo e que exploraremos abaixo.

Devido ao seu histórico de luta por libertação da escravização no Brasil, a Capoeira é uma prática de libertação por excelência (BREDA, 2010). Seus fundamentos e seu universo simbólico podem promover a conscientização de situações de opressão devido ao processo de colonização.

Freire entende que o processo de conscientização advém também de "corpos conscientes" nos quais a consciência é intencionada ao mundo (1987, p. 38), ressaltando a importância da consciência corporal nos processos de transformação pessoal e coletiva decorrentes do ler e pronunciar o mundo. David Le Breton (2007, p. 7) nos ensina que "antes de qualquer coisa a existência é corporal". Afirma que é do corpo que emergem significações que fundamentam a existência coletiva e individual, denotando "um eixo de relação com o mundo" (LE BRETON, 2007, p. 7).

A Capoeira tem como um de seus fundamentos centrais o diálogo de corpos nas interações dos jogos. Aprendemos a gingar, movimentando-nos, conscientizando-nos. Interagimos com outros capoeiristas para aprendermos com eles, em uma conversa corporal entre meia-lua, bênção, chapa (golpes de capoeira), esquiva (defesa), dança malandra da mandinga ${ }^{2}$ dos capoeiristas, que a desenvolvem a partir do momento que aprendem a ter autonomia de si e do outro. Pode assim iniciar o encontro de homens e mulheres para o Ser mais. O aprendizado do Jogo constitui-se em comunhão, constatando o que o autor ressalta:"ninguém educa ninguém, como tampouco ninguém se educa a si mesmo: os homens se educam em comunhão, mediatizados pelo mundo" (FREIRE, 1987, p. 39). As(os) capoeiristas assim compartilham, através de seus corpos e de seus discursos, suas diferentes visões de mundo e experiências de vida, educando-se para novos olhares e releituras do mundo em que vivem.

Este reconhecimento do corpo através da ginga e das movimentações leva a uma libertação dos movimentos e, consequentemente, da consciência. Jaime Lima, o Mestre Jaime de Mar Grande (2016) diz que "A padronização do movimento é a prisão do pensamento, ser livre é pensar e movimentar-se livremente". Visto ser o corpo um canal por onde iniciam as transformações individuais e coletivas, consagra um veículo para o Ser Mais nas relações cotidianas e sociais. 
Como diria Vicente Ferreira de Pastinha, O Mestre Pastinha (ARAÚJO, 2015, p. 36), "o corpo é um grande sistema de razão. Por detrás de nossos pensamentos acha-se um Ser poderoso, um sábio desconhecido". Esta sabedoria tatua-se em memórias dérmicas pelas normas sociais no corpo inscritas, mas também no espaço de transgressão e de rebeldia (SILVA, 2009), típico movimento dos capoeiristas que, tanto nas rodas de capoeira como na grande roda da vida, representadas pelos movimentos cotidianos em sociedade, "gingam" enfrentando as inúmeras opressões impostas pelo sistema.

Estes gingados, constituídos de aprendizados e relacionamentos determinados pelo nosso ser/estar no mundo, se dão através do corpo, porque vivemos socialmente através dele em relações de poder (SILVA, 2009). O corpo é assim para o indivíduo, um espaço privilegiado de múltiplos canais de comunicação, sobretudo, quando vivenciados em grupo (ARAÚJO, 2015).

O ritual vivenciado nas rodas de capoeira permite a experiência de relembrar em conjunto (ABIB, 2005). Segundo Olga Von Simson (1991 apud $A B I B, 2005$, p. 101), o ato de compartilhar a memória é "um trabalho que constrói sólidas pontes de relacionamento entre os indivíduos - porque alicerçadas numa bagagem cultural comum - e que, talvez por isso, conduza a ação". A pedagogia da interação de grupo, através da bagagem cultural, representada por fundamentos e símbolos que valorizam positivamente a herança africana no Brasil, pode contribuir para a tomada de consciência da realidade opressora em que muitas e muitos estão inseridos e assim, como diria Paulo Freire (1987), posicionar-se criticamente nela.

Essa bagagem cultural vivenciada pelos grupos de capoeira através de seus Mestres e de seu universo simbólico, como exemplo as cantigas de capoeira, fazem com que seus participantes rememorem coletivamente os tempos de escravidão e a luta do povo negro por liberdade e equidade na sociedade brasileira. Algumas cantigas representam indignações do povo perante questões e personalidades históricas distorcidas e não valorizadas pela história oficial, conferindo pertencimento histórico e social (BREDA, 2010) como a ladainha “Dona Isabel", de Mestre Tony Vargas (2010):

Dona lsabel que história é essa

Dona Isabel que história é essa de ter feito abolição

De ser princesa boazinha que libertou a escravidão

To cansado de conversa, to cansado de ilusão 
Abolição se fez com sangue que inundava este país

Que o negro transformou em luta,

Cansado de ser infeliz

Abolição se fez bem antes e ainda há por se fazer agora

Com a verdade da favela,

E não com a mentira da escola

Dona Isabel chegou a hora

De se acabar com essa maldade

De se ensinar aos nossos filhos, O quanto custa a liberdade

Viva Zumbi nosso rei negro,

Que fez-se herói lá em Palmares

Viva a cultura desse povo,

A liberdade verdadeira

Que já corria nos Quilombos, E já jogava capoeira

lêêê viva Zumbi...

Conforme Abib (2005), rememorar este passado traz a tona e denuncia conflitos originários no tempo da escravidão que se perpetuam até hoje, de violência e opressão exercidas contra marginalizados sociais que até hoje persistem. Este processo de conscientização coletiva, dos quais esses sujeitos são protagonistas, pode promover concretas possibilidades de ação perante a realidade opressora. É nessa realidade, na qual circula o universo cultural e, portanto, temático da educação proporcionada pela capoeira, que se inaugura o diálogo da educação como prática de liberdade (FREIRE, 1987).

O pertencimento social e histórico construído desde a consciência e vivência corporal às reflexões simbólicas desta manifestação cultural 
também possibilitam o fortalecimento de corpos e identidades individuais, historicamente marginalizados e negligenciados pela estrutura opressora classista e racista brasileira.

Aprendemos a classificar os sujeitos pelas formas como eles se apresentam corporalmente, atribuindo significados pelas aparências e marcas. Embora, "os corpos não são, pois, tão evidentes como usualmente pensamos. Nem as identidades são decorrência direta das'evidências' dos corpos" (LOURO et al., 2000, p. 8). O corpo extravasa, assim, o domínio biológico, pois nele está inscrito, tal como uma história, a nossa cultura, as nossas vivências que se manifestam no olhar, no andar, no sentir, nos gestos, nas vestimentas, na comunicação, nas punições, no pensamento, na intuição, no afeto, no amor (SILVA, 2009). Então, olhar o corpo como o óbvio e esperar que este revele a identidade de gênero ou raça somente pela marca biológica, é arriscado e ainda mais marcante quando não assumimos a ambiguidade e inconstância que atravessam a identidade.

Rosângela Araújo (2015) nos ajuda a compreender que a manifestação cultural da capoeira construída com base na alteridade e diferença sustenta uma pedagogia articulada à identidade que ressalta dimensões pedagógicas como a ancestralidade, o pertencimento, a organização coletiva e a solidariedade. Estas conduzirão à aquisição e visibilidade para direitos específicos dos representantes da população oprimida e definindo outras formas possíveis de portar-se frente ao contexto racial e social brasileiro.

A autora discorre que nesta concepção de capoeira comprometida com o reconhecimento positivo de pensar a África e os africanos, são reforçados nos imaginários de seus praticantes valores ancestralmente construídos pelas civilizações dominadas. Dessa maneira, contribui para a instauração de uma cosmovisão africana no Brasil, pela qual a vivência nas tradições que representam tais saberes se torna um caminho para a construção de identidades possíveis.

Na elaboração de estratégias e práticas de resistência negra e do antirracismo, podemos encontrar também "críticas ao modelo hierárquico da sociedade brasileira frente às diversas vias de construção da cidadania" (ARAÚJO, 2015, p. 39), sendo assim um processo crítico de construção de emancipação frente às opressões. Esta filosofia de vida, que tem como base educacional fundante o relacionamento mestre(a)-discípula(o), calca-se nos imaginários e representações de um universo simbólico mitopoético que fortalece a presença do sujeito enquanto cidadão consciente e atuante na realidade. Estabelecendo relações com os estudos de Freire já citados, esta educação realizada pela vivência na Capoeira proporciona, para pessoas 
negras e não negras, privilegiadas socialmente ou não, a possibilidade da construção do Ser Mais comprometido com seu ser/estar no mundo.

Estes corpos, considerados mercadorias metamorfoseadas conforme as modelagens prescritas do capital; corpos renegados pelas perversidades do legado escravocrata e das demais lógicas opressoras, subvertem a ordem vigente para ser corpo memória, corpo resistência, corpo capoeira. Estes corpos, representando a coletividade dos que se unem sob os fundamentos da filosofia da capoeira, representam corpos que lutam, na roda de capoeira e na roda da vida; corpos expressão, de liberdade e de identidades antes desestruturadas pela supremacia econômica e racial; corpos natureza, morada da ancestralidade, composto de elementos sagrados que nos unem a terra; corpos conhecimento, que faz da(o) capoeirista música(o), brincante, historiadora(o), aprendiz; e, por fim, corpos criança, que nos faz por as mãos no chão, ficar de pernas para o ar e voltar a sorrir, desarmando o sistema e recuperando a ludicidade tanto de jogar como de viver.

Esta identificação polissêmica do corpo, gingado pelos afetosaprendizagens da capoeiragem, ressaltam o papel educativo e pedagógico que esta manifestação cultural traz em seus fundamentos. Sua construção de resistência/sobrevivência no histórico da sociedade brasileira confere características emancipatórias aos aprendizes dessa manifestação, possibilitando o estabelecimento de conexões com os pressupostos emancipatórios freirianos que a caracterizam como uma prática cultural libertadora.

\section{CONCLUSÃO}

A proposta freiriana apresenta a cultura como libertação humana e como uma forma de repensar o papel social e político da educação. Por isso, convida-nos a trabalhar com empenho para humanizar o mundo, recorrendo à reconstrução cultural e a uma práxis transformadora do ser humano. Uma práxis que problematiza, criando condições para que os sujeitos compreendam e desmistifiquem a realidade envolvente e que situem o seu ser e estar no mundo.

Paulo Freire (1997, p. 100) faz-nos pensar no que é ser, "Não sou se você não é, não sou, se proíbo você de ser". Esta frase não se limita no significado de proibir o outro de viver a sua vida, mas sim e, por conseguinte, a minha existência (o meu ser) que possibilita e coopera para que a existência do outro (o ser do outro) se concretize, sendo nesse sentido que verdadeiramente se é. Na perspectiva Freiriana a nossa existência aflora a permanente busca de ser mais. Em tempo algum o ser está completo, ele descobre-se numa constante inconclusão, numa metamorfose que se aclara neste pensamento "o mundo não é, o mundo está sendo" (FREIRE, 1997, p. 100). 
Por isso o ser só se realiza no movimento de estar sendo que se manifesta na busca de ser, que é traduzida no contínuo da inconclusão, o qual o autor designa de inédito viável. Perante uma filosofia da libertação, o inédito viável perscruta um caminho de superação das situações limite (FREIRE, 1997), transformando-as num desafio que se desdobra no cessar da injustiça possibilitando um mundo melhor. Este pensamento não se confunde num determinismo teológico ou filosófico, mas é tido como uma possibilidade histórica que suplanta, através de um processo educativo uma prática domesticadora.

Considera-se que o ser significa o ser da consciência na existência, daí nasce a necessidade de conscientização do ser planetário no qual todas as ações positivas ou negativas repercutem-se num elo de causa e efeito que influencia de certa maneira alguém e algum local.

O ser completo colmata a sua existência em conjunto com o estar numa luta pelo encontro da conscientização durante o seu percurso de vida, ultrapassando obstáculos que impedem a sua libertação.

Nesta linha de pensamento, o estar no mundo significa integrar-se no mundo, a partir de lutas que em reflexão se atinja a criação do ser. A capoeirista e o capoeirista, ao criar consciência de si e de sua história através de seu corpo e do contato com a herança histórica abarcada no universo simbólico vivido na roda e no jogo da capoeira, pode construir habilidades para integrar-se criticamente na realidade que a(o) oprime e agir para transformá-la.

A valorização positiva de suas identidades e da historicidade dos processos sociais pelos quais passaram os povos marginalizados na sociedade brasileira levam a uma conscientização da realidade entre opressores e oprimidos, promovendo caminhos em direção ao Ser mais e ao processo de libertação. Corpos e mentes livres e autônomos contribuirão para a formação de agentes críticos de mudanças e uma sociedade equalitária e justa.

Ao jogar capoeira, portanto, a(o) "capoeirista escreve com o corpo a sua própria história" (BITTENCOURT, 2015). Sendo sujeito e protagonista dessa história, contribui para uma cultura na qual oprimidas e oprimidos, conscientes de suas realidades, contribuem para uma cultura que, como diria Marilena Chauí (2014, p. 147) possa sugerir outra lógica, "uma racionalidade que navega contra a corrente, cria seu curso, diz não e recusa que a única história possível seja aquela concebida pelos dominantes". As ideias e conceitos freirianos, portanto, continuam atuais e condizentes com uma educação para a emancipação humana tecida pelas manifestações culturais como a Capoeira. 


\section{BODY, CULTURE AND PAULO FREIRE: CAPOEIRA AS A WAY OF EDUCATION FROM THE PERSPECTIVE OF HUMAN EMANCIPATION}

AвSTRACT: This theoretical article aims to relate Freire's concepts of being more, conscientization, freedom, reading the world, limit situations, oppressed oppressor, with the foundations and the symbolic universe of Capoeira, Afro-Brazilian cultural manifestation of struggle and resistance of historically marginalized people in order to enable a libertarian education based on culture. By presenting foundations embodied in corporeity and symbologies, such as cantigas, which confer social and historical belonging, as well as the positive valorization of historically silenced identities, the practice of capoeira is a potential cultural manifestation towards the Be More, leading to the critical insertion in reality of the oppressed people, so that they act on it for human emancipation.

KEYWORDS: Capoeira. Body. Paulo Freire. Libertarianeducation.

\section{CUERPO, CULTURA Y PAULO FREIRE: LA CAPOEIRA COMO UNA POSIBILIDAD DE EDUCACIÓN EN LA PERSPECTIVA DE LA EMACIPACIÓN HUMANA}

RESUMÉN: El presente artículo, de base teórica, tiene por objetivo relacionar conceptos freirianos de ser más, concienciación, libertad, leer el mundo, situaciones límite, oprimido/ opresor, con los fundamentos y el universo simbólico de la Capoeira, manifestación cultural afrobrasileña de lucha y reistencia de pueblos históricamente marginalizados, con el fin de posibilitar una educación libertaria con base en la Cultura. Por presentar fundamentos configurados en la corporeidad y en simbologías, como las cantigas, que confieren pertenencia social y histórica, además de la valorización positiva de identidades históricamente silenciadas, la práctica de la capoeira se configura como potencial manifestación cultural en dirección al Ser Más, Ilevando la inserción crítica de oprimidos en la realidad, para que en ella actúen dirigidos a la emancipación humana.

Palabras clave: Capoeira. Cuerpo. Paulo Freire. Educación Libertadora.

\section{NOTAS}

1 A Roda de Capoeira configura-se de maneiras distintas conforme suas vertentes, Angola e Regional, ocorrendo variações de acordo com os diferentes grupos e suas linhagens de Mestres. Na Capoeira Angola, geralmente se apresenta uma bateria composta por três berimbaus (Gunga, Médio e Viola), dois pandeiros, reco-reco, agogô e atabaque. Na Capoeira Regional, segundo a configuração original de Mestre Bimba, criador do estilo, é composta por um berimbau e dois pandeiros. Ao centro da roda, os capoeiristas desenvolvem o jogo ao ritmo do toque dos berimbaus. 
2 Segundo Renato Vieira (1998), a Mandinga atribui identidade ao jogo da capoeira Angola. Ela denota tanto a malícia do capoeirista durante o jogo, fingindo golpes, iludindo o adversário para um possível ataque, como também uma conexão com dimensões sagradas, se conectando com o Axé, força vital e cósmica para as religiões afro-brasileiras.

\section{REFERÊNCIAS}

ABIB, P. R. J. Capoeira Angola: cultura popular e o jogo de saberes na roda. Campinas, CMU; Salvador: Edufba, 2005.

ANTONACCI, M. A. Memórias ancoradas em corpos negros. 2. ed. São Paulo: Educ, 2014.

ARAÚJO, R. C. É preta kalunga: a capoeira angola como prática política entre os angoleiros baianos: anos 80-90. Rio de Janeiro: MC\&G, 2015.

BITTENCOURT, R. Jogar capoeira é escrever com seu corpo a sua história. Altura: 924 pixels. Largura: 421 pixels. 59063 bytes. Formato JPEG. Disponível em: $<$ https://www. facebook.com/photo.php?fbid=1068255803215163\&set=g.571847349613682\&type $=1$ \&theater $>$. Acesso em: 20 set. 2015.

BREDA, O. A Capoeira como prática educativa transformadora. Educação Pública. Rio de Janeiro, Agosto de 2010. Disponível em: <http://www.educacaopublica.rj.gov.br/ biblioteca/educacao fisica/0009.html >. Acesso em: 01 nov. 2016.

CHAUÍ, M. Conformismo e Resistência: Aspectos da Cultura Popular no Brasil. In: SANTIAGO, H. (Org.). Conformismo e Resistência. Belo Horizonte: Autêntica; São Paulo, Fundação Perseu Abramo, 2014. (Coleção Escritos de Marilena Chauí, 4). p. 15-147.

FALCÃO, J. L. C. A Capoeira também educa. Revista Sprint, Rio de Janeiro, v.54, p. 34$38,1991$.

FREIRE, P. Pedagogia do Oprimido. 17. ed. Rio de Janeiro: Paz e Terra, 1987.

. Cartas a Cristina. Rio de Janeiro: Paz e Terra, 1994.

. Pedagogia da Autonomia. Rio de Janeiro: Paz e Terra, 1996.

. Pedagogia da Esperança.São Paulo: Paz e Terra, 1997.

. Pedagogia da Indignação: ser e estar no mundo. 2. ed. São Paulo: Paz e Terra, 2015.LE BRETON, D. A Sociologia do Corpo. 2. ed. Petrópolis: Vozes, 2007.

LIMA, J. [Sem título]. 2016. 1 banner.

LOURO, G. L. et al. O Corpo Educado. Pedagogias da sexualidade. 2. ed. Tradução Tomaz Tadeu da Silva. Belo Horizonte: Autêntica, 2000.

MAGALHÃES, P. A. Arte ou luta? As gingas da capoeira entre o folclore e o esporte. In: SIMPLÍCIO, F.; POCHAT, A.(Org.). Pensando a capoeira: dimensões e perspectivas. Rio de Janeiro: MC\&G, 2015. (Coleção Capoeira Viva, 3). p. 149-170. 
MAGALHÃES, P. A. Jogo de Discursos: a disputa por hegemonia na tradição da capoeira angola baiana. 2011. 196 f. Dissertação (Mestrado em Ciências Sociais) - Faculdade de Filosofia e Ciências Humanas, Universidade Federal da Bahia, Salvador, 2011.

OLIVEIRA, J. P.; LEAL, L. A. P. Capoeira, identidade e gênero: ensaios sobre a história social da capoeira no Brasil. Salvador: EDUFBA, 2009.

REGO, W. Capoeira Angola: ensaio socioetnográfico. 2. ed. Rio de Janeiro: MC\&G, 2015. (Coleção Capoeira Viva, n 5).

SCALDAFERRI, S. Só o tempo de faz mestre: Pastinha, Bimba, Maré e Noronha- a adaptação da capoeira em Salvador. In: SIMPLÍCIO, Franciane; POCHAT, Alex. (Org.). Pensando a capoeira: dimensões e perspectivas. Rio de Janeiro: MC\&G 2015. (Coleção Capoeira Viva, 3). p. 173-188.

SILVA, M. C. P. Do corpo objeto ao sujeito histórico: perspectivas do corpo na história da educação brasileira. Salvador: Edufba, 2009.

VARGAS, T. Dona Isabel. 2010. 1 video (4:18 min). Online, son, color. Disponível em: <https://www.youtube.com/watch?v=-6TeZY9UVOc>. Acesso em: 05 nov. 2016.

VIEIRA, L. R. O Jogo de Capoeira: Cultura Popular no Brasil. Rio de Janeiro: Sprint, 1998.

Anastácia Schroeder: É mestra em educação pelo Programa de Pós- Graduação em Educação da Universidade Federal da Bahia (PPGE - FACED - UFBA), atuando como pesquisadora do srupo HCEL (História da Cultura Corporal, Educação, Esporte, Lazer e Sociedade), na linha de pesquisa Educação, Cultura Corporal e Lazer.

E-mail: anastacia.bio.danca@gmail.com

JoAna Rita Lopes Vieira: É doutoranda do Programa de Pós-Graduação em Educação da Universidade Federal da Bahia (PPGE - FACED - UFBA), atuando como pesquisadora do grupo HCEL (História da Cultura Corporal, Educação, Esporte, Lazer e Sociedade), na linha de pesquisa Educação, Cultura Corporal e Lazer.

E-mail:marialaranja@gmail.com

Maria Cecília de Paula Silva: É professora do Programa de Pós- Graduação em Educação da Universidade Federal da Bahia (PPGE - FACED - UFBA), e coordenadora do grupo de pesquisa HCEL (História da Cultura Corporal, Educação, Esporte, Lazer e Sociedade), na linha de pesquisa Educação, Cultura Corporal e Lazer.

E-mail: cecilipaula@gmail.com 